ORIGINAL ARTICLE

\title{
Systematic review of the optimal fluid for dilutional exchange transfusion in neonatal polycythaemia
}

\author{
K A de Waal, W Baerts, M Offringa
}

Arch Dis Child Fetal Neonatal Ed 2006;91:F7-F10. doi: 10.1136/adc.2004.063925

See end of article for authors' affiliations

...................

Correspondence to: Koert A de Waal, Department of Neonatal Medicine, Royal Prince Albert Hospital, Missenden Road, Camperdown, NSW 2050, Australia; k.a.dewaal@amc.uva.nl

Accepted 13 April 2005

\begin{abstract}
Objectives: Several studies have shown the efficacy of dilutional exchange transfusion (DET) in reducing haematocrit $(\mathrm{Ht})$ and relieving clinical symptoms in neonatal polycythaemia. We conducted a systematic review to determine the efficacy of crystalloid versus colloid solutions used in DET in an effort to identify the best solution to replace red blood cells.

Methods: The Cochrane Library, MEDLINE, and EMBASE were searched for relevant randomised controlled trials. Quality assessment and data analysis were performed using the methods and software of the Cochrane Collaboration. Relative risk (RR) and weighted mean difference (WMD) were calculated as measures of effect for categorical and continuous outcome data, respectively. Ninety five percent confidence intervals $(95 \% \mathrm{Cl})$ were calculated and a fixed effect model was used for meta-analysis.

Results: Six studies with a total of 235 newborns matched our inclusion criteria. When comparing crystalloid and colloid replacement solutions for DET, there was a clinically unimportant difference in $\mathrm{Ht}$ at 2-6 $\mathrm{h}$ and at $24 \mathrm{~h}$ in favour of colloidal solutions (WMD 2.29\% $(95 \% \mathrm{Cl} 1.28$ to 3.31$)$ and $1.74 \% 195 \% \mathrm{Cl}$ 0.80 to 2.68), respectively). This difference in post DET Ht was more evident when normal saline was compared to plasma but absent when normal saline was compared to $5 \%$ albumin.

Conclusion: There is little difference in effectiveness between plasma, 5\% albumin, and crystalloid solutions. Since normal saline is cheap, readily available, and does not carry the potential risk of transfusion associated infection, normal saline is the optimal dilutional fluid for exchange transfusion in polycythaemic neonates.
\end{abstract}

OR hyperviscosity OR exchange transfusion) AND (infant, newborn) combined with a sensitive filter for retrieval of reports of controlled trials. ${ }^{9}$ No language restrictions were applied. Bibliographies of all selected articles and review articles which included information on the topic were reviewed for other relevant articles. Abstracts from the Society for Pediatric Research and the European Society for Pediatric Research from 1989 to 2002 were also searched.

\section{Inclusion criteria and outcome measures}

To be included in the review, articles had to fulfil the following selection criteria: the study had to be a randomised controlled trial comparing the use of crystalloid with colloid solutions, in which the subjects were assigned prospectively to one or two (or more) interventions by random allocation or some quasi-random method of allocation (for example, alternating); the participants had to be term or preterm newborn infants up to 28 days of age; outcome measures had to include a pre- and post-DET haematocrit, our primary outcome; and there had to be a report on the relief of PC related clinical symptoms and/or complications of the procedure. Disagreement about inclusion was resolved by discussion.

\section{Quality assessment and data abstraction}

The quality of each article included in the review was assessed independently by two reviewers (KW, WB) in terms of the presence of treatment allocation concealment, blinding of carers and assessors to intervention, completeness of assessment of all randomised individuals, and blinded

Abbreviations: $95 \% \mathrm{Cl}, 95 \%$ confidence interval; DET, dilutional exchange transfusion; $\mathrm{Ht}$, haematocrit; $\mathrm{PC}$, polycythaemia; RR, relative risk; WMD, weighted mean difference
Cochrane Controlled Trial Register, and EMBASE using the following search terms: (polycythaemia OR blood viscosity 


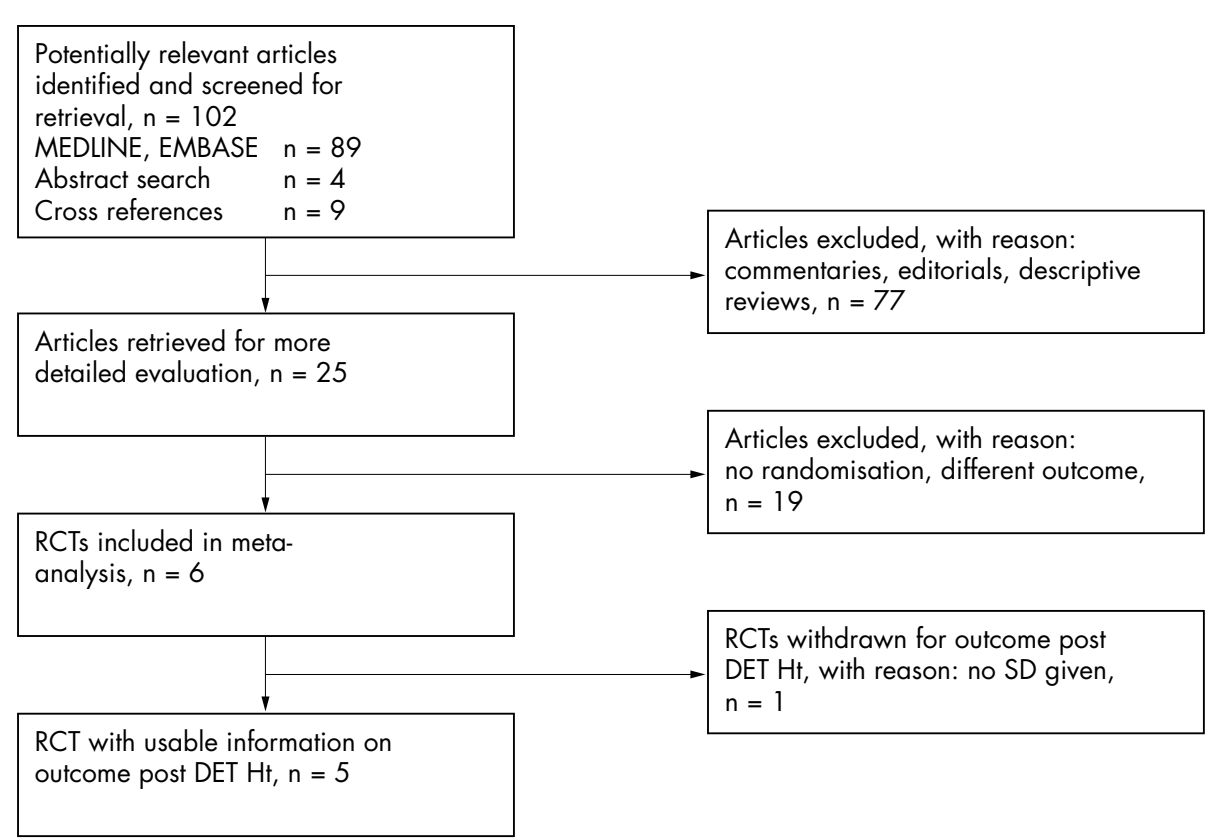

Figure 1 Trial flow characteristics. DET, dilutional exchange transfusion; Ht, haematocrit; SD, standard deviation; RTCs, randomised clinical trials.

outcome measurement. Two reviewers extracted the data from each trial $(\mathrm{KW}, \mathrm{WB})$.

\section{Data analysis}

Review Manager software developed by the Cochrane Collaboration (version 4.2) was used for data management and analysis. The relative risk (RR) and weighted mean difference (WMD) were calculated for categorical and continuous data, respectively. Ninety five percent confidence intervals $(95 \%$ CI) were calculated and a fixed effect model was used for meta-analysis.

\section{RESULTS}

Description of selected studies and quality assessment Figure 1 summarises the trial flow. Eighty nine studies were identified using the computerised search. Commentaries, descriptive reviews, and clinical trials that did not comply with our review questions were excluded, leaving 12 studies to be retrieved for more detailed evaluation. A further nine studies were identified from the cross references of selected articles and another four potentially relevant abstracts were found through a search of the abstracts from the Society for Pediatric Research and the European Society for Pediatric Research. Nineteen of these 25 papers were excluded according to the pre-defined criteria, leaving six randomised trials with a total of 235 newborns that fulfilled the inclusion criteria. ${ }^{10-15}$ Jan et al did not provide standard deviations for the mean on the post-DET Ht outcome, and as a consequence the results on this outcome cannot be weighted in the metaanalyses. However, these authors did provide information on relief of clinical symptoms and complications of the procedure.

The DET procedure was adequately described in five of the six studies and all studies used the same calculation to determine the exchange volume needed. Table l shows clinical details of included studies.

The exact method of randomisation was described in only two of the six studies ${ }^{10}{ }^{11}$ and no study reported on blinding of the intervention. In none of the six studies was it possible to determine whether the caregivers and those assessing the outcomes of interest were blinded to the treatment allocation. There was complete short term follow up of all randomised infants in the included studies. No long term follow up data were presented in any of the studies.

\section{Quantitative data synthesis}

The pooled results of the different trials are presented in tables 2 and 3.

Table 1 Characteristics of included studies

\begin{tabular}{|c|c|c|c|c|}
\hline Study & $\mathbf{n}$ & Participants & Interventions & Procedures \\
\hline Tapia $^{12 *}$ & 29 & Polycythaemic newborns & $\begin{array}{l}\text { Plasma } v 5 \% \text { albumin } v \\
\text { normal saline }\end{array}$ & Unknown route and desired $\mathrm{Ht}$ \\
\hline Deorari ${ }^{13}$ & 30 & $\begin{array}{l}\text { Venous } \mathrm{Ht}>65 \% \text { with symptoms after } \\
\text { screening high risk newborns }\end{array}$ & Plasma $v$ normal saline & $\begin{array}{l}22 \text { umbilical, } 8 \text { peripheral, } \\
\text { desired } \mathrm{Ht} 55 \%\end{array}$ \\
\hline Roithmaier $^{10}$ & 20 & $\begin{array}{l}\text { Venous } \mathrm{Ht}>65 \% \text { with symptoms after } \\
\text { screening cord blood }\end{array}$ & Plasma $v$ Ringer solution & 20 umbilical, desired $\mathrm{H}+55 \%$ \\
\hline Wong ${ }^{11}$ & 103 & $\begin{array}{l}\text { Venous } \mathrm{Ht} \geqslant 65 \% \text { with symptoms or } \\
\text { venous } \mathrm{Ht} \geqslant 70 \%\end{array}$ & $5 \%$ albumin $v$ normal saline & $\begin{array}{l}16 \text { umbilical, } 87 \text { peripheral, } \\
\text { desired } \mathrm{H}+55 \%\end{array}$ \\
\hline Krishnan $^{14}$ & 27 & $\begin{array}{l}\text { Venous } \mathrm{Ht}>65 \% \text { with symptoms or } \\
\text { venous } \mathrm{Ht}>70 \% \text { after screening all newborns }\end{array}$ & Plasma $v$ normal saline & $\begin{array}{l}27 \text { peripheral, desired } \mathrm{H}+55 \% \text {, } \\
\text { capillary post } \mathrm{DET} \mathrm{Ht}\end{array}$ \\
\hline $\operatorname{Jan}^{15}$ & 26 & $\begin{array}{l}\text { Venous } \mathrm{Ht} \geqslant 65 \% \text { with symptoms after } \\
\text { screening all newborns }\end{array}$ & Plasma $v$ normal saline & $\begin{array}{l}\text { Umbilical and peripheral, } \\
\text { desired } \mathrm{H}+55 \%\end{array}$ \\
\hline
\end{tabular}


Table 2 Quantitative data synthesis, post DET Ht

\begin{tabular}{|c|c|c|c|c|}
\hline Outcome & Studies* & Crystalloid $†$ & Colloidt & WMD $(95 \% \mathrm{Cl})$ \\
\hline \multicolumn{5}{|l|}{ Crystalloid $v$ colloid (all) } \\
\hline 2-6 h post DET Ht & 5 & 115 & 111 & $2.29(1.28$ to 3.31$)$ \\
\hline $24 \mathrm{~h}$ post $\mathrm{DET} \mathrm{Ht}$ & 5 & 115 & 120 & $1.74(0.80$ to 2.68$)$ \\
\hline \multicolumn{5}{|l|}{ Normal saline $v$ plasma } \\
\hline 2-6 h post DET Ht & 4 & 62 & 61 & 2.34 (0.94 to 3.73$)$ \\
\hline $24 \mathrm{~h}$ post $\mathrm{DET} \mathrm{Ht}$ & 4 & 62 & 60 & 2.81 (1.74 to 3.89 ) \\
\hline \multicolumn{5}{|c|}{ Normal saline $\vee 5 \%$ albumin } \\
\hline 2-6 h post DET Ht & 1 & 53 & 50 & $1.00(-1.14$ to 3.14$)$ \\
\hline $24 \mathrm{~h}$ post DET Ht & 2 & 63 & 60 & $-0.35(-2.06$ to 1.35$)$ \\
\hline
\end{tabular}

*Number of studies reporting on outcome; tnumber of patients in group.

$95 \% \mathrm{CI}, 95 \%$ confidence interval; DET, dilutional exchange transfusion; $\mathrm{Ht}$, haematocrit; WMD, weighted mean difference.

When comparing crystalloid and colloid replacement solutions, there was a clinically unimportant difference in $\mathrm{Ht}$ at $2-6 \mathrm{~h}$ and $24 \mathrm{~h}$ after the DET in favour of colloidal solutions (WMD 2.29\% (95\% CI 1.28 to 3.31 ) and $1.74 \%$ (95\% CI 0.80 to 2.68 ), respectively). This difference in post DET Ht was slightly more evident when normal saline was compared to plasma but was not present if normal saline was compared to $5 \%$ albumin. There was evidence of statistical heterogeneity of treatment effect in these meta-analyses.

Symptoms before and after the DET procedure were reported in three studies; however, "relief of symptoms" was not well defined in these studies. No differences in incidence of persistent jitteriness, persistent hypoglycaemia, or persistent gastro-intestinal problems were indicated. In a total of 226 polycythaemic patients, only one repeat DET was necessary in a newborn in the saline group. No procedural complications were reported in any of the studies.

Two studies reported on viscosity, but pooling of these data was not feasible due to the different laboratory methods used. Both studies showed no significant differences in postDET viscosity.

\section{DISCUSSION}

The results of this review indicate that a DET is effective in reducing the haematocrit in polycythaemic newborns. Colloid solutions are more effective in reducing the haematocrit than crystalloid solutions, with a mean difference of $2.29 \%$ at $2-$ $6 \mathrm{~h}$ post DET. Plasma appears to be most effective in reducing haematocrit, followed by normal saline, then albumin. Higher loss to the extravascular space of crystalloid solutions as compared to plasma is the probable explanation for these findings. ${ }^{10}$

The small differences in post-DET haematocrits between children treated with crystalloids and colloids seem to be of no clinical significance. We found no evidence that the proportion of patients relieved of clinical symptoms and the number of patients needing a repeat DET were different between treatment groups. It should be noted, however, that "relief of symptoms" was not well defined in the three studies reporting on this parameter and no clinical data were reported at all in the three remaining studies. One can only assume that relief of clinical symptoms was adequate in the latter, because no repeat DETs were necessary.

We found evidence of statistical heterogeneity of treatment effect in the meta-analyses. This could be caused by methodological imperfections in several included studies, by differences in the selection of participants for the studies, or by differences in the DET solutions used. Allocation concealment was adequate in only two studies and blinding of carers and assessors of clinical outcome was not performed in any of the studies. The latter potential source of bias pertains to the scoring of relief of symptoms only, as a reading of Ht cannot be biased by knowledge of treatment allocation. There was no major clinical diversity between the studies. The proportion of small for gestational age patients in each treatment group was reported in four studies and did not differ significantly. Tapia et al did not provide a definition for PC, but mean preDET haematocrit in this study was higher than $70 \% .{ }^{12}$ We feel that pooling of the selected studies' results is justified despite these differences.

As a last point, viscosity data were reported in only two studies. For practical purposes, indications for DET and evaluation of outcome of the procedure were based on haematocrit values in most studies. The question remains whether haematocrit or viscosity is most accurate in the assessment of the severity of polycythaemia and of the efficacy and safety of alternative dilutional fluids. This question can only be answered in prospective studies involving both haematocrit and viscosity measurements, in combination with standardised documentation of clinical symptoms

\section{CONCLUSION}

Dilutional exchange transfusion is effective in reducing haematocrit and in relieving clinical symptoms related to PC. There is no clinically important difference among plasma, $5 \%$ albumin, normal saline, or Ringers solution in reducing haematocrit. Since normal saline is cheap, readily available, and does not carry the potential risk of transfusion associated infection, normal saline is the optimal fluid for dilutional exchange transfusion in polycythaemic neonates.

Table 3 Quantitative data synthesis, clinical symptoms, and complications

\begin{tabular}{lllll}
\hline Outcome & $\mathbf{n}^{*}$ & Crystalloidt & Colloidt & RR (95\% CI) \\
\hline Persistent jitteriness & 2 & $3 / 17$ & $4 / 21$ & $1.11(0.27$ to 4.60$)$ \\
Persistent hypoglycaemia & 2 & $9 / 29$ & $2 / 26$ & $3.12(0.91$ to 10.65$)$ \\
Persistent GE problems & 2 & $4 / 25$ & $4 / 29$ & $1.30(0.41$ to 4.16$)$ \\
Second DET & 5 & $1 / 115$ & $0 / 111$ & Not estimable \\
Complications of procedure & 4 & $0 / 105$ & $0 / 101$ & Not estimable \\
\hline
\end{tabular}

*Number of studies reporting on outcome; tnumber of patients with outcome/total number of patients.

$95 \% \mathrm{Cl}, 95 \%$ confidence interval; DET, dilutional exchange transfusion; $\mathrm{GE}$, gastro-intestinal; RR, relative risk. 


\section{What is already know about this topic}

- A partial or dilutional exchange transfusion is recommended for treatment of symptomatic neonatal polycythaemia

- The efficacy of dilutional exchange transfusion in reducing haematocrit and relieving clinical symptoms has been shown

\section{Authors' affiliations}

K A de Waal, W Baerts, Department of Paediatrics, Division of Neonatology, Isala Clinics Zwolle, Zwolle, The Netherlands M Offringa, Department of Neonatology, Emma Children's Hospital, Academic Medical Centre, Amsterdam, The Netherlands

Competing interests: none declared

\section{REFERENCES}

1 Werner EJ. Neonatal polycythemia and hyperviscosity. Clin Perinatol 1995;22(3):693-710.

2 Wirth FH, Goldberg KE, Lubchenco LO. Neonatal hyperviscosity: I. Incidence. Pediatrics 1979;63(6):833-6.

3 Amit M, Camfield PR. Neonatal polycythemia causing multiple cerebral infarcts. Arch Neurol 1980;37(2):109-10.

4 Kliegman RM, Fanaroff AA. Neonatal necrotizing enterocolitis: a nine-year experience. Am J Dis Child 1981:135(7):603-7.

5 Black VD, Lubchenco LO, Luckey DW, et al. Developmental and neurologic sequelae of neonatal hyperviscosity syndrome. Pediatrics 1982;69(4):426-31.

6 Luchtman-Jones L, Swartz A, Wilson D. The blood and the hematopoietic system. In: Fanaroff AA, Martin RJ, eds. Neonatal-perinatal medicine: diseases of the fetus and newborn. St Louis, MO: Mosby, 1997:1201-97.

\section{What this study adds}

- There is no clinically important difference among plasma, $5 \%$ albumin, normal saline, or Ringers solution when used in a dilutional exchange transfusion in reducing haematocrit

- Normal saline is the optimal fluid for dilutional exchange transfusion in polycythaemic neonates

7 Letsky E. Polycythemia in the newborn. In: Rennie JM, ed. Textbook of neonatology. Edinburgh, UK: Churchill Livingstone, 1999:834-8.

8 Schimmel MS, Bromiker R, Soll RF. Neonatal polycythemia: is partial exchange transfusion justified? Clin Perinatol 2004;31(3):545-53.

9 Robinson KA, Dickersin K. Development of a highly sensitive search strategy for the retrieval of reports of controlled trials using PubMed. Int J Epidemiol 2002;31(1):150-3.

10 Roithmaier A, Arlettaz R, Bauer K, et al. Randomized controlled trial of Ringer solution versus serum for partial exchange transfusion in neonatal polycythaemia. Eur J Pediatr 1995;154(1):53-6.

11 Wong W, Fok TF, Lee $\mathrm{CH}$, et al. Randomised controlled trial: comparison of colloid or crystalloid for partial exchange transfusion for treatment of neonatal polycythaemia. Arch Dis Child Fetal Neonatal Ed 1997;77(2):F115-8

12 Tapia J, Solivelles X, Grebe G, et al. Evaluation of different solutions for erythropheresis in the treatment of neonatal polycythemia. Pediatr Res 1992;31:1614, 271A.

13 Deorari AK, Paul VK, Shreshta L, et al. Symptomatic neonatal polycythemia: comparison of partial exchange transfusion with saline versus plasma. Indian Pediatr 1995;32(11):1167-71.

14 Krishnan L, Rahim A. Neonatal polycythemia. Indian J Pediatr 1997;64(4):541-6.

15 Jan M, Ahmad S, Charoo B, et al. Neonatal polycythemia: comparison of partial exchange transfusion with plasma versus normal saline. JK Practitioner 2000;7(3):195-6. 